\title{
A topografia da sala de aula online: reflexões a partir de uma experiência de pesquisa-formação com professores de ciências ${ }^{+}$
}

\author{
Enadieliton dos Santos ${ }^{1}$ \\ Licenciando do curso de Física Licenciatura \\ Universidade Federal de Alagoas - Campus Arapiraca \\ Arapiraca - AL \\ Ivanderson Pereira da Silva ${ }^{1}$ \\ Universidade Federal de Alagoas - Campus Arapiraca \\ Arapiraca - AL
}

\section{Resumo}

A disciplina "Temas de física na pesquisa-formação de professores" foi ofertada na modalidade online, no segundo semestre de 2017, nos Programas de Pós-graduação (PPG) em Educação em Ciências e em Ensino de Física da Universidade Federal do Rio Grande. Além dos alunos desses PPG, participaram dessa disciplina, alunos e professores dos cursos de Física Licenciatura da Universidade Federal do Pampa e da Universidade Federal de Alagoas (UFAL), bem como alunos do PPG em Ensino de Ciências e Matemática da UFAL. Tal experiência reuniu 18 sujeitos que compuseram grupos e exploraram temas de Física na perspectiva da pesquisa-formação. Dado o perfil dos sujeitos e da proposta de construção de uma sala de aula interativa, emergiu o seguinte problema de pesquisa: Qual a topografia da sala de aula construída a partir das interações online no contexto da pesquisa-formação? Trata-se de uma investigação qualitativa, classificada como um estudo de interação por meio de dados escritos. Como recurso de análise, foi realizado o mapeamento das interações dos sujeitos. Dentre os módulos que compuseram esta disciplina, foi analisado apenas o módulo 5 intitulado "O cordel no ensino de Física". A escolha se justificou pelo fato deste conter o fórum

\footnotetext{
${ }^{+}$The topography of the online classroom: reflections from a experience of the research-training with science teachers

* Recebido: setembro de 2018.

Aceito: janeiro de 2019.

${ }^{1}$ E-mails: enadieliton.ufal@gmail.com; ivanderson@gmail.com
} 
com o maior número de interações. Nesse movimento de pesquisa, analisamos seu desenho didático, material didático, a docência online e a topografia da sala de aula constituída a partir das interações dos sujeitos. Como resultados constatamos que apesar das intervenções dos sujeitos que ocuparam a posição discente indicarem majoritariamente uma comunicação todos-todos, do desenho didático estar apoiado na flexibilidade e na interatividade do ciberespaço, bem como do material didático ter sido produzido de forma dialógica, multimidiática e hipertextual, as intervenções dos sujeitos que ocuparam a posição docente acabaram por centralizar as interações, resultando numa topografia intermediária entre a sala de aula tradicional e a sala de aula interativa.

Palavras-chave: Interação Online; Fóruns Online; Pesquisa-Formação.

\begin{abstract}
The subject "Physics subjects in research-teacher training" was offered online in the second semester of 2017, in the Postgraduate Programs (PPG) in Science Education and Physics Teaching at the Federal University of Rio Grande. In addition to the students of these PPGs, students and professors of the Licentiate Physics courses of the Federal University of Pampa and the Federal University of Alagoas (UFAL) participated as well as students of the PPG in Science and Mathematics Teaching at UFAL. This experience brought together 18 subjects who composed groups and explored subjects of Physics from the perspective of research-training. Given the profile of the subjects and the proposed construction of an interactive classroom, the following research problem emerged: What is the topography of the classroom built from online interactions in the context of research-training? It is a qualitative investigation, classified as an interaction study through written data. As an analysis resource, the mapping of subjects' interactions was performed. Among the modules that composed this discipline, only module 5 was titled "The cordel in the teaching of Physics". The choice was justified by the fact that it contained the forum with the greatest number of interactions. In this research movement, we analyze its didactic design, didactic material, online teaching and the topography of the classroom constituted from the interactions of the subjects. As a result we find that although the interventions that occupied the student position indicate mostly all-all communication, of the didactic design supported by the flexibility and interactivity of cyberspace, as well as the
\end{abstract}


didactic material was produced in a dialogic, multimedia and hypertextual way, the interventions of the subjects that occupied the teaching position ended up centralizing the interactions, resulting in an intermediate topography between the traditional classroom and the interactive classroom.

Keywords: Interaction Online; Online Forums; Research-Training.

\section{Introdução}

A cibercultura revela uma relação entre a técnica e a vida social que tem reconfigurado as práticas formativas e de produção do conhecimento em seus sentidos lato e stricto senso. Esse quadro tem permitido o desenvolvimento de abordagens interventivasinvestigativas como a pesquisa-formação. Essa tem sido apropriada e ressignificada nos diferentes contextos educativos mediados por tecnologias digitais da informação e comunicação (TDIC).

Nesse contexto, pesquisas nacionais têm demonstrado que o desenho didático, o material didático, a docência e a avaliação da aprendizagem online, que se dão em ambientes virtuais de aprendizagem (AVA), apontam para a pesquisa-formação online como um campo do saber, e ao mesmo tempo uma abordagem didática, fundamentalmente interdisciplinar (SANTOS, 2017). Nesse contexto todos são protagonistas de sua própria aprendizagem, são (co)responsáveis pela aprendizagem uns dos outros, são sujeitos e ao mesmo tempo objetos do fazer pedagógico e das pesquisas que dele emergem.

A pesquisa-formação, do ponto de vista metodológico, se configura pela organização de grupos que alternam de forma sistemática os papéis, docente e discente, no AVA, "em torno de operar o objeto aperfeiçoável” (HECKLER et al. 2013, p. 5). Inicialmente um grupo assume a docência enquanto os demais grupos ocupam a função de alunos. Ao concluir sua intervenção, esse primeiro grupo que assumiu a docência, passa a ocupar o lugar de alunos e um segundo grupo assume a docência.

A partir das experiências vivenciadas pelos sujeitos, emergem questões de pesquisa as quais podem ser exploradas na perspectiva da reflexão-ação, de seus percursos, ou dos percursos de seus pares. Para Ribeiro e Santos (2016, p. 298), “a pesquisa-formação, enquanto postura epistemológica e política, nos coloca no caminho da práxis, ou seja, os saberes teóricos articulados aos saberes da ação dos professores e alunos situados em contextos formativos".

Dentre os cenários em que se têm experimentado esse tipo de abordagem investigativa-formativa, destacamos o componente curricular "Temas de física na pesquisa-formação de professores". Trata-se de uma disciplina que foi ofertada na modalidade online, no segundo semestre de 2017, nos Programas de Pós-graduação (PPG) em Educação em Ciências e de Ensino de Física da Universidade Federal do Rio Grande (FURG). Além dos alunos desses 
PPG, participaram dessa disciplina, alunos de iniciação científica e professores dos cursos de Física Licenciatura, da Universidade Federal do Pampa (UNIPAMPA) e da Universidade Federal de Alagoas (UFAL), bem como alunos do PPG em Ensino de Ciências e Matemática da UFAL. Tal experiência reuniu 18 pesquisadores que compuseram grupos, propuseram e exploraram temas de Física na perspectiva da pesquisa-formação online. Tratam-se de sujeitos distribuídos nas regiões sul e nordeste do Brasil e que são oriundos dos municípios de Candiota (RS), Rio Grande (RS), Maceió (AL), Coité do Nóia (AL), Arapiraca (AL) e dois participantes venezuelanos. São sujeitos diversos do ponto de vista cultural, étnico, de gênero, sexualidade, níveis econômicos, níveis de formação acadêmica, bem como de diferentes faixas etárias (entre 22 e 75 anos).

Recuero (2011) considera que a interação no ciberespaço pode ser compreendida na forma de conexão entre pares de atores e que seu mapeamento pode demonstrar que tipos de relações esses sujeitos estabeleceram. Nesse sentido, consideramos que: a) o AVA pode ser compreendido como a transmaterialização da sala de aula no ciberespaço; b) os sujeitos da pesquisa eram professores e estudiosos do campo da Educação em Ciências; e c) que dispomos, na contemporaneidade, de recursos teórico-metodológicos que nos permitem identificar possíveis inovações didáticas. A partir de tais considerações, emergiu o seguinte problema de pesquisa: Qual a topografia da sala de aula construída a partir das interações online no contexto da pesquisa-formação?

Trata-se de uma pesquisa de natureza qualitativa (FLICK, 2009; SAMPIERI; CALLADO; LUCIO, 2013) que, por tomar como fonte de dados as interações no fórum que obteve maior número de registros ao longo da disciplina, se classifica como um estudo de interação por meio de dados escritos (COSTA; PARAGUAÇU, 2011). Como recurso de análise, foi realizado o mapeamento das interações online de acordo com a metodologia proposta por Silva, Lessa e Mercado (2015) que, para esse fim, utilizaram o software CmapTools $<$ https://cmap.ihmc.us/>.

A motivação para esse estudo resultou, em primeiro plano, da necessidade de socializar com professores e pesquisadores experiências de pesquisa-formação que apontem caminhos para a construção de salas de aula online cada vez mais flexíveis e interativas. Além disso, também foi motivo para a proposição desse estudo o fato dos autores desse estudo terem participado da elaboração e da execução do módulo 5, "Cordel no ensino de Física", e vislumbrarem no relato e na análise dessa experiência a possibilidade de que mais e melhores experiências de pesquisa-formação possam ser desenvolvidas.

Assim, apresentamos nesse estudo, num primeiro momento, uma descrição da experiência; e, por fim, o mapeamento e análise da rede de interações constituída. Ao longo dessa narrativa, analisamos o desenho didático, material didático, a docência online e da topografia da sala de aula a partir das interações dos sujeitos. Esses resultados estão dispostos a seguir. 


\section{A disciplina Temas de Física na pesquisa formação de professores}

A oferta da disciplina "Temas de Física na pesquisa formação de professores" se deu na modalidade online, por meio do AVA Moodle da FURG $<$ http://www.moodle.sead.furg.br/course/view.php?id=4925>, bem como por meio da realização de encontros quinzenais síncronos via recurso da webconferência (inicialmente via Skypee posteriormente via Hangout). Os 18 sujeitos envolvidos compuseram grupos, de acordo com as instituições de ensino superior (IES) envolvidas e esses propuseram temas de Física que foram explorados na perspectiva da pesquisa-formação online. Para isso, no AVA Moodle, todos os sujeitos foram designados com o perfil de professor para que pudessem criar e editar os desenhos didáticos e os materiais didáticos de suas propostas de unidades curriculares ou módulos do curso.

O resultado desse primeiro movimento foi a proposição de oito módulos com diferentes temas de Física, além do material de apresentação e o módulo final de sistematização. No entanto, no decurso da disciplina, essa proposta teve de ser ajustada em função das discrepâncias entre os calendários acadêmicos das IES envolvidas. Com esse ajuste, os módulos sete e oito foram suprimidos e sua oferta teve de ser remanejada para um momento posterior. Foram elaborados os seguintes módulos:

- Mural de Apresentação da Disciplina (Grupo 1 - FURG);

- Módulo 1: Nosso espaço-tempo de diálogo sobre os temas de Física (Grupo 1 FURG);

- Módulo 2: Modelagem da energia mecânica com vídeos e simulações (Grupo 2 FURG);

- Módulo 3: Estudo da termodinâmica na perspectiva investigativa e interdisciplinar (Grupo 3 - FURG);

- Módulo 4: Estudo dos circuitos elétricos com auxílio de interfaces/artefatos da web (Grupo 4 - FURG);

- Módulo 5: Cordel no ensino de Física (Grupo 5 - UFAL);

- Módulo 6: Física no trânsito (Grupo 6 - UNIPAMPA);

- Sistematização das emergências na disciplina (Todos os grupos).

Dentre os módulos desenvolvidos, destacamos o "Módulo 5 - Cordel no ensino de Física”, executado no período de 09 a 22 de novembro de 2017, por esse ter abrigado o fórum que registrou o maior número interações no decurso da disciplina. Esse módulo foi desenvolvido pelo grupo da UFAL (Grupo 5), composto por um estudante de graduação do curso de Física Licenciatura do Campus Arapiraca, por um estudante do Mestrado em Ensino de Ciências e Matemática e por um professor do ensino superior vinculado a esses cursos. 
Os objetivos desse módulo foram: favorecer a compreensão do conceito de cordel, sua construção histórica e classificação; bem como possibilitar a exploração de cordéis produzidos com vistas a apoiar a prática pedagógica em Física e desafiar os sujeitos a produzirem um cordel que enfocasse um tema de Física.

Dentre as atividades que constaram no módulo 5 foi proposto o fórum de discussão intitulado "O Cordel no Ensino de Física" que ficou disponível para interação durante as duas semanas de execução do módulo (09 a 22 de novembro de 2017). Durante esse período, foram registrados 63 comentários produzidos por 17 sujeitos, dentre os quais três ocuparam a função docente e os demais ocuparam a função discente.

Para que se possa compreender como se configurou a topografia da sala de aula descreveremos como foi pensado e desenvolvido o desenho didático, o material didático, a docência online e o mapeamento das interações online.

\section{II.1 O desenho didático}

Segundo Santos e Silva (2009, p. 269), na sala de aula online, todos os elementos de uma aula ou de um curso (conteúdos de aprendizagem, propostas de trabalho, avaliações e interfaces de construção da comunicação e do conhecimento) são estruturados a partir de um desenho didático, que pode ser compreendido como a

estrutura de apresentação do conjunto de conteúdos e de situações de aprendizagem compostos e dispostos estrategicamente de modo a serem utilizados pelo docente e pelos cursistas com a finalidade de potencializar a construção coletiva da comunicação, do conhecimento, da docência, da aprendizagem e da avaliação.

Nesse sentido, ao construir o desenho didático para a educação online, os idealizadores das aulas e cursos online não podem perder de vista potencialidades do ciberespaço como a flexibilidade e a interatividade. O conceito de flexibilidade (espacial e temporal) diz respeito à possibilidade de "acompanhar regularmente um curso de qualidade, interagindo com o professor, com os conteúdos de aprendizagem e com os colegas de classe" (SILVA, 2012a, p. 12) sem se deslocar para outro lugar. Já a interatividade, permite ao aprendiz, "o diálogo, a cocriação e o controle dos processos de aprendizagem mediante dispositivos e interfaces de gestão, de autoria e de comunicação" (SILVA, 2012a, p. 12).

Nesse sentido, o desenho didático do modulo 5, intitulado "Cordel no ensino de Física" foi pensado de modo que seus elementos constitutivos favorecessem a coautoria dos sujeitos envolvidos, obedecendo aos princípios da flexibilidade e da interatividade.

Isso se justifica porque os idealizadores desse desenho didático concordaram com a máxima de que "quando qualquer sistema, metodologia ou tecnologia de educação nos imagina apenas como consumidores de algo já mastigado, deglutido e digerido, boa parte do seu poder revolucionário se perdeu" (BLIKSTEIN; ZUFFO, 2012, p. 28). Nesse sentido, se operou com uma proposta aberta à coautoria dos sujeitos que ocupavam a função discente. 
No mural principal, primeira interface com a qual os sujeitos se deparam, os idealizadores do módulo utilizaram um banner com xilogravuras que simbolizavam a literatura de cordel e centralizaram o título do módulo para chamar a atenção ao tema proposto. As cores utilizadas foram o preto e o branco pelo fato dos folhetos de cordel originalmente obedecerem a esse padrão de cores, conforme a Fig. 1 .

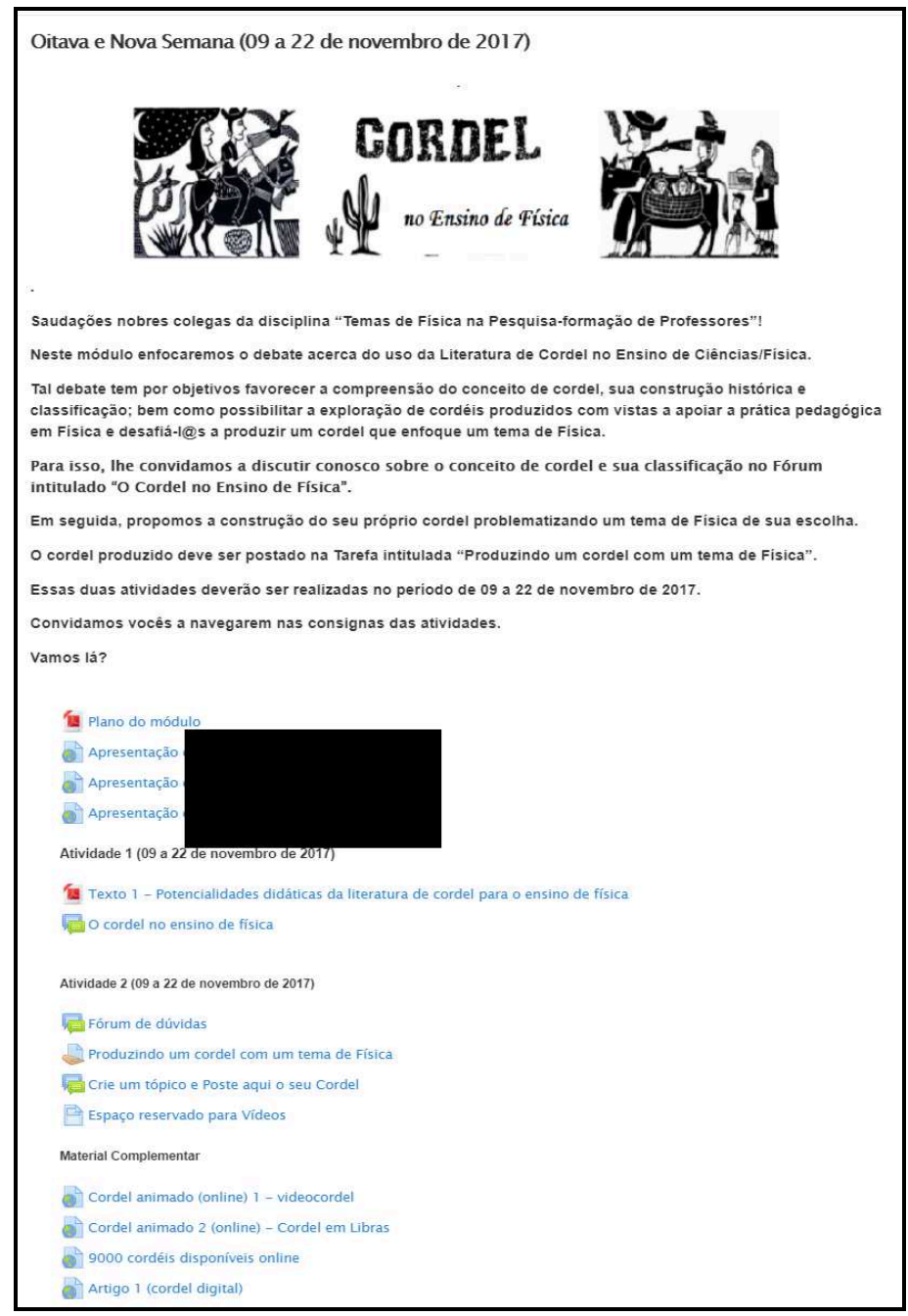

Fig. 1 - Mural principal do módulo "Cordel no ensino de Física”. Fonte: Captura de tela.

Para Silva (2012b, p. 62) o mural principal "procura motivar, interessar, envolver e provocar os cursistas à aprendizagem. Deve exprimir a marca de qualidade da qual vai partir o curso, sem jamais enganar os cursistas com um perfil de qualidade que não se mantenha na continuidade das aulas". Nesse sentido, a mensagem da consigna contida no mural principal continha uma saudação inicial cuja "intenção era acolher os cursistas, dar-lhes boas-vindas e incentivar a sua participação" (SILVA, 2012b, p. 65).

Essa mensagem inicial se preocupava em posicionar os sujeitos envolvidos como colegas, sem hierarquias de titulação, ou distinção de função no curso. Na sequência destacava o 
foco do módulo, os objetivos de aprendizagem, as atividades propostas e o prazo que tinham para cumpri-las. Além disso, disponibilizava o plano do módulo (com ementa, objetivos, conteúdos, metodologia, proposta de avaliação da aprendizagem e referências de obras utilizadas; vídeos curtos de até dois minutos com a apresentação dos idealizadores do módulo; duas atividades em interfaces online (dentre as quais o fórum analisado nesta investigação) e alguns materiais para leitura complementar.

O convite lançado a partir do mural principal, continha no intertexto o objetivo de que o ambiente pudesse ser um espaço de profunda construção coletiva, em que todos pudessem interagir, (co)criar, compartilhar informações e experiências. Esse desenho didático foi arquitetado a partir de um paradigma interativo, sequencial, atento às possibilidades de dúvida quanto ao tema e ao material apresentado, considerando uma práxis ${ }^{2}$ que articulasse dialeticamente teoria e prática, que favorecesse a autoavaliação dos sujeitos, a apresentação de modelos/exemplos do tipo de material que se buscava construir nas atividades propostas, bem como variados formatos de apresentação do material didático hipertextual (texto, vídeos, sites). A função desses materiais foi servir de "introdutores das temáticas a serem estudadas, ou mesmo orientadores de estudos mais aprofundados" (BELISÁRIO, 2012, p. 144).

Segundo Silva (2012b, p. 58), para promover um cenário de uma sala de aula interativa e flexível é fundamental que o desenho didático do curso garanta pelo menos três aspectos essenciais:

Participação colaborativa: participar não é apenas responder "sim” ou "não”, prestar contas ou escolher uma opção dada, significa intervenção na mensagem como cocriação da emissão e da recepção.

Bidirecionalidade e dialógica: a comunicação é produção conjunta da emissão e da recepção, os dois pólos codificam e decodificam.

Conexões em teias abertas: a comunicação supõe múltiplas redes articulatórias de conexões e liberdade de trocas, associações e significações.

Nesse sentido, de modo específico, para além do mural principal, podemos verificar tais elementos no desenho didático da consigna do fórum intitulado "Cordel no ensino de Física", a partir da Fig. 2.

Como se pode verificar, a consigna do fórum obedece a mesma lógica do mural principal do módulo 5. Ao fazer uma saudação inicial que posiciona os sujeitos como colegas, sem distinções, apresenta de forma objetiva a proposta do fórum, indica o material de leitura obrigatória, suscita questões norteadoras para auxiliar os sujeitos a iniciarem os debates e os convida a trazer para o fórum outros materiais que encontrarem ou que tenham conhecimento

\footnotetext{
2 Segundo Vásquez (1968, p. p. 117) apud Kuenzer (2018, p. 1) práxis “é atividade teórica e prática que transforma a natureza e a sociedade; prática, na medida em que a teoria, como guia da ação, orienta a atividade humana; teórica, na medida em que esta ação é consciente".
} 
de sua existência. Esse desenho didático, ao convocar os sujeitos a participarem ativamente por meio de seus posicionamentos fundamentados e da contribuição com novos materiais, vislumbrou a "transição da lógica da distribuição (transmissão) para a lógica da comunicação (interatividade)" (SANTOS; SILVA, 2009, p. 271).

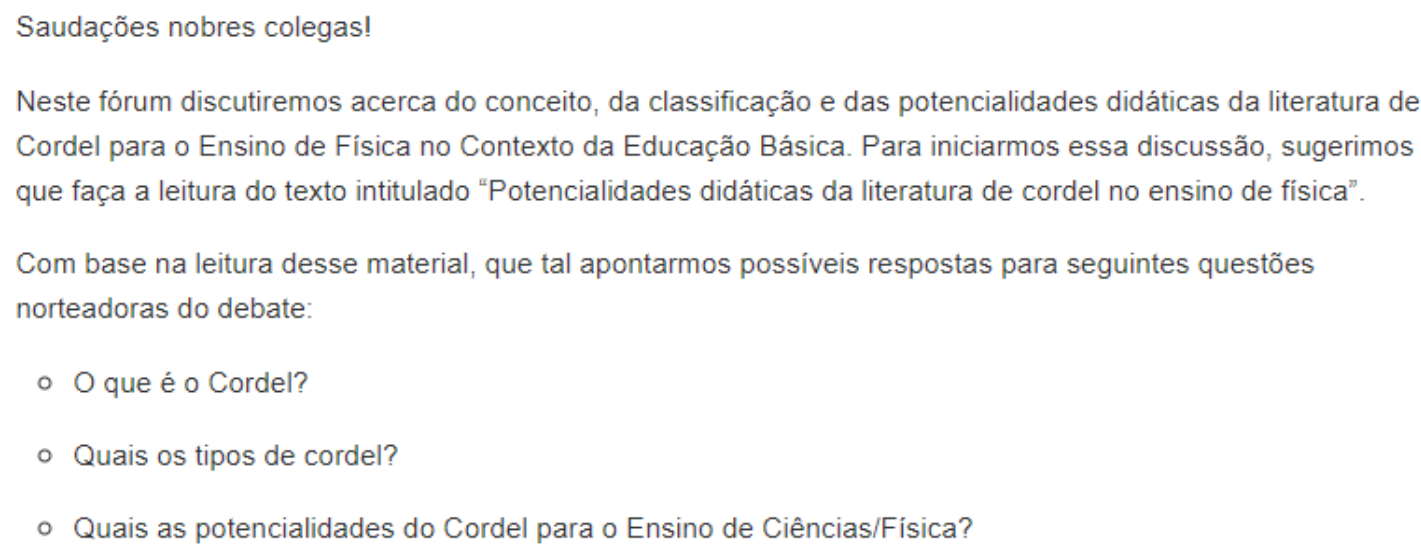

Fique à vontade para nos brindar com novos materiais que contribuam com esse debate tais como artigos, charges, tirinhas, cordéis, vídeos, etc.

Vamos lá?

Fig. 2 - Consigna do fórum. Fonte: Captura de tela.

\section{II.2 O material didático}

Segundo Moran (2012, p. 43), no contexto da educação online, "os papéis do professor se multiplicam, diferenciam-se e complementam-se, exigindo uma grande adaptação e criatividade diante de novas situações, propostas, atividades". Dentre os papéis assumidos pelos sujeitos que ocuparam a função docente dos módulos da disciplina "Temas de Física na pesquisa-formação", figura o da produção de um material didático aberto à coautoria dos demais sujeitos que ocupavam respectivamente a função discente.

Assim, os idealizadores do módulo 5, ao construírem a consigna do fórum intitulado "O Cordel no Ensino de Física", chamaram a atenção dos sujeitos para a necessidade de se apropriarem de um material de leitura no formato impresso para web (em extensão .pdf) disponível no mural principal e que tinha como título "Potencialidades didáticas da literatura de cordel no ensino de Física". A introdução desse material continha a seguinte mensagem:

Saudações nobres colegas da disciplina "Temas de Física na Pesquisa-Formação de Professores"!

Sejam muito bem vindos a esse módulo! 
Aqui enfocaremos as potencialidades didáticas da literatura de cordel para o ensino de Física no contexto da Educação Básica.

O material que disponibilizamos para leitura tem por objetivo apontar as origens, as características, uma possível classificação, bem como as potencialidades didáticas da literatura de cordel para o ensino de Física.

Naturalmente esse material não intenta fazer uma exegese da temática, ou dar conta à exaustão dessa questão. Longe disso! Deverá ser entendido como um pontapé inicial para o nosso debate que será construído coletivamente no Fórum intitulado " $O$ cordel no ensino de física".

É importante esclarecer que o nosso fórum é um ambiente convidativo à participação de todos e que essa participação pode se materializar por meio da postagem de comentários ou materiais como artigos, imagens, cordéis, tirinhas, charges, vídeos, etc.

Fique à vontade!

A casa é sua!

Assim sendo, desejamos uma excelente leitura do material, um rico debate no fórum e que esse módulo seja uma experiência significativa e engrandecedora para todos nós!

Um forte abraço e sucesso nas produções!

(SANTOS; SANTOS; SILVA, 2017, p. 1)

Ao pesquisarem acerca do material didático impresso para a EaD, Almeida e Cavalcante (2009), identificaram a presença constante de marcadores relacionais como, por exemplo, "você", bem como o uso de pronomes em $1^{\text {a }}$ pessoa do plural e pronomes possessivos. Essa característica é considerada pelas autoras como uma "linguagem adequada para textos de apresentação em cursos a distância" (ALMEIDA; CAVALCANTE, 2009, p. 63).

Segundo Costa e Motta Filho (2009, p. 74), o material didático impresso para a educação online, "transcende a sua natureza informativa, como ocorre na modalidade presencial, para se tornar parceiro do professor e (co)mediador na construção do conhecimento". Nesse sentido, ao longo do material de leitura sugerido, se discutiu, a partir de uma revisão de literatura, as origens da literatura de cordel, as possibilidades didáticas que esse tipo de recurso pode oferecer para aulas de Física, exemplos de cordéis em sextilha e septilha e, por fim, fazia um convite aos sujeitos:

Agora é chegado o momento de darmos continuidade à construção do texto a partir do fórum intitulado "O Cordel no Ensino de Física".

Neste fórum discutiremos acerca do conceito, da classificação e das potencialidades didáticas da literatura de Cordel para o Ensino de Física no Contexto da Educação Básica.

Com base na leitura desse material, que tal apontarmos possíveis respostas para seguintes questões norteadoras do debate:

O que é o Cordel?

Quais os tipos de cordel? 


\section{Quais as potencialidades do Cordel para o Ensino de Ciências/Física?}

Fique à vontade para nos brindar com novos materiais que contribuam com esse debate tais como artigos, charges, tirinhas, cordéis, vídeos, etc.

Vamos lá?

(SANTOS; SANTOS; SILVA, 2017, p. 12)

A linguagem que esse material de leitura adotou seguiu as orientações de "apresentar o tema a estudar numa linguagem clara e coloquial com uma moderada densidade de informações" (ALMEIDA, 2009, p. 106). Além disso, apresentava orientações acerca das atividades e convidava "o aluno à troca de opiniões, a fazer perguntas" (ALMEIDA, 2009, p. 106). Esse tipo de linguagem que caracteriza o material didático na educação online se justifica porque, segundo Costa e Motta Filho (2009, p. 68),

O material didático na EaD possui função primordial no processo de mediação do conhecimento, considerando ser ele o elemento-chave para que haja a conexão dialógica entre o professor e o aluno, pois se trata do elemento articulador que promove a facilitação do ensino-aprendizagem, podendo ser o diferencial de uma proposta pedagógica, e o agente da apropriação crítica do conhecimento por parte do aluno.

Nesse sentido, o material didático para a educação online não se confunde com as tradicionais apostilas ou materiais de leitura, clássicos da educação presencial, e que têm como função principal transmitir informações. Segundo Belisário (2012, p. 140), esse material precisa "apresentar-se numa linguagem dialógica que, na ausência física do professor, possa garantir um certo tom coloquial, reproduzindo mesmo, em alguns casos, uma conversa entre professor e aluno, tornando a leitura leve e motivadora". Além disso, o material didático para a educação online deve considerar ainda a linguagem hipertextual.

Segundo Marcuschi (2001, p. 86) o hipertexto "se caracteriza, pois, como um processo de escritura/leitura eletrônica multilinearizado, multisequencial e indeterminado, realizado em um novo espaço de escrita". Para Gomes (2011, p. 15), por constituir enquanto linguagem característica do ciberespaço, o hipertexto "possui como elemento central a presença de links, que podem ser palavras, imagens, ícones etc.”. Ao clicar nesses links, os sujeitos são remetidos "a outros textos, permitindo percursos diferentes de leitura e de construção de sentidos a partir do que for acessado e, consequentemente, pressupõe certa autonomia de escolha dos textos a serem alcançados através de links" (GOMES, 2011, p. 15). Na opinião de Rezende e Cola (2004, p. 94), o hipertexto é um "sistema computacional que representa nodos de informações, em geral, textuais, organizados não sequencialmente, por meio de ligações conceituais entre palavras-chaves".

Assim, é possível considerar que a linguagem hipertextual se caracteriza principalmente por sua não linearidade; espacialidade topográfica ilimitada, não hierárquica; multimodalidade e interatividade (KOCH, 2009; BRASILEIRO; MARTINS, 2013; MACEDO et al., 2017; NUNES; LIMA, 2018). Ao interagir com o hipertexto o leitor se torna coautor de novos 
textos, na medida em que constrói junto com os autores dos textos originais, percursos singulares de leitura e (re)escrita. Nesse sentido, "diferentemente do que o texto de um livro convencional, o hipertexto não tem uma única ordem de ser lido. A leitura pode dá-se em muitas ordens. Têm múltiplas entradas e múltiplas formas de prosseguir" (MARCUSCHI, 2001, p. 86). Segundo Silva (2012b, p. 56), "a sala de aula inspirada no hipertexto permite que o cursista teça sua autoria operando em vários percursos e leituras plurais". Nesse sentido, o material didático do módulo 5 foi disponibilizado de forma articulada e aberta a outros cenários para além do AVA e em variados formatos midiáticos.

Dentre os formatos em que o material didático do módulo 5 foi disponibilizado, destacamos: material impresso para web (com extensão.pdf); e vídeos amadores de apresentação dos idealizadores do módulo 5 (esses vídeos foram gravados de forma amadora por cada um dos idealizadores do módulo a partir de seus smartphones e foram postados no Youtube. Os links dos vídeos foram incorporados ao material didático do módulo 5 e esse mecanismo evitou que se postasse o vídeo diretamente no AVA e o deixasse mais pesado). Tal esforço se deu no sentido de "oferecer múltiplas informações (em imagens, sons, textos, etc.), [...], ensejar (oferecer ocasião de...) e urdir (dispor entrelaçados os fios da teia, enredar), múltiplos percursos para conexões e expressões" (SILVA, 2012b, p. 57).

Além do material produzido pelos idealizadores, foram disponibilizados materiais complementares tais como: a) um vídeo que apresentava e discutia o cordel animado produzido pela equipe da $\mathrm{UFPE}^{3}$, b) um vídeo que apresentava a ideia de cordel animado com o uso da Língua Brasileira de Sinais (LIBRAS) ${ }^{4}$ produzido pela equipe do projeto "Acessibilidade em Bibliotecas Públicas" do Ministério da Cultura; c) a indicação do site da "Revista Prova Verso e Arte" que disponibiliza mais de 9000 cordéis online; d) o artigo intitulado "Cordel digital: interfaces hipertextuais da literatura de cordel" de autoria de José Severino da Silva e Renato da Silva, publicado no volume 7, número 16, em 2014, pela Revista UNIABEU ${ }^{6}$.

\section{II.3 Docência online}

Para Silva (2012b, p. 58), no contexto da sala de aula online, o professor "será formulador de problemas, proponente de situações, arquiteto de percursos, mobilizador das inteligências múltiplas e coletivas na construção do conhecimento". Nesse sentido, para identificar como interagiram os sujeitos no fórum intitulado "O Cordel no Ensino de Física", e de modo específico, se a docência online observou a necessidade de assumir uma postura problematizadora, propositiva e mobilizadora, foram extraídos os inícios e os finais das contribuições textuais dos sujeitos que ocupavam a posição discente e também daqueles que ocupa-

\footnotetext{
${ }^{3}$ Disponível em: < https://www.youtube.com/watch?v=PXa3eYOh96I >

${ }^{4}$ Disponível em: <https://www.youtube.com/watch?v=KQChyvNe2Ac>

${ }^{5}$ Disponível em: <https://www.revistaprosaversoearte.com/literatura-de-cordel-9000-obras-disponiveis-online/>

${ }^{6}$ Disponível em: <http://revista.uniabeu.edu.br/index.php/RU/article/view/1307/pdf_100>
} 
vam a posição docente. Esses quatro grupos de excertos textuais nos permitiram compor quatro nuvens de palavras que podem ser visualizadas na Fig. 3.

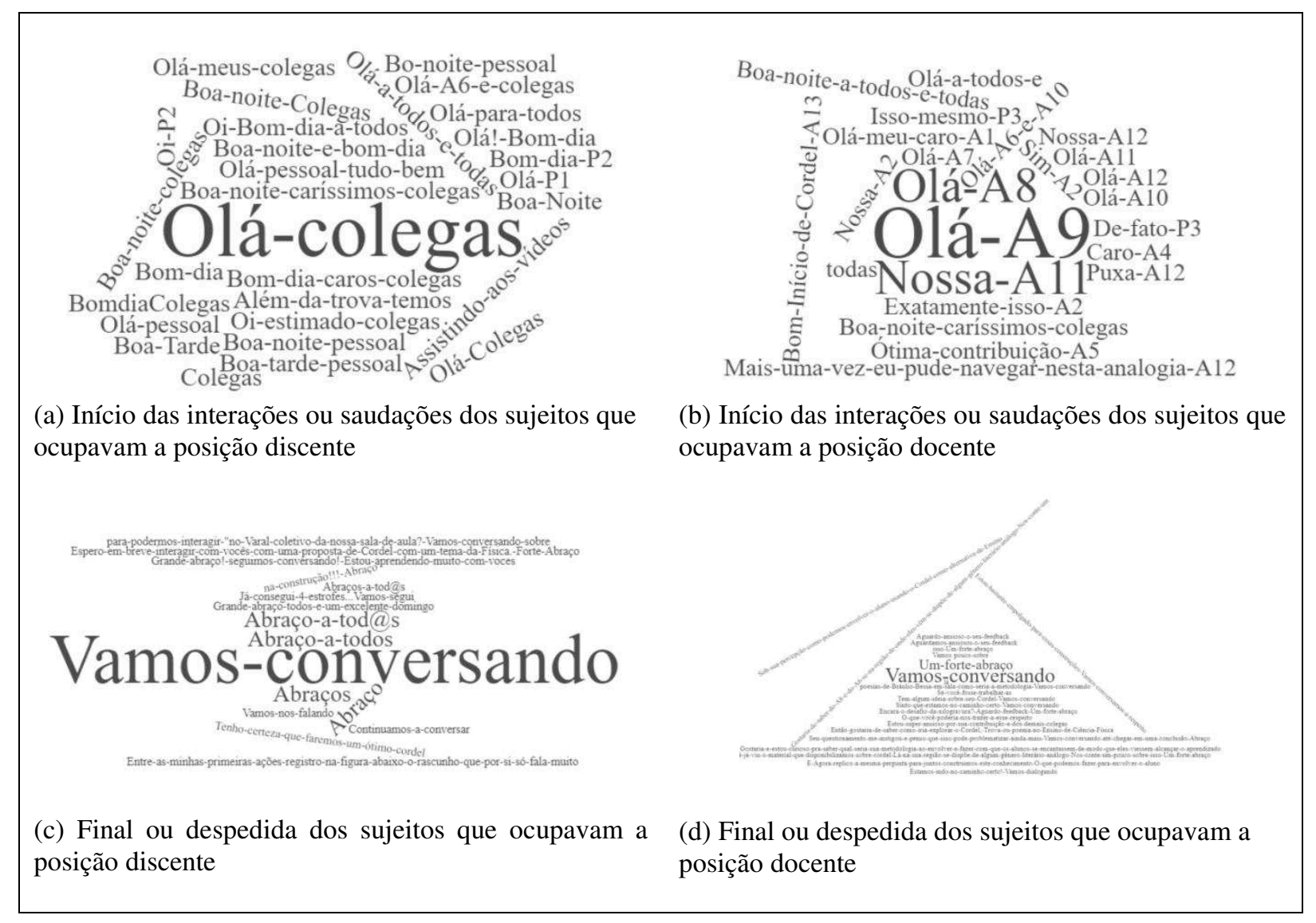

Fig. 3 - Nuvens de palavras das frases de acolhida e despedida no fórum de discussão.

Fonte: Fórum de discussão "Cordel no Ensino de Física".

A criação das nuvens de palavras foi realizada a partir do software online WordClouds $<$ https://www.wordclouds.com/>. O princípio da composição de nuvens de palavras se dá com base na recorrência dos termos. Quanto mais recorrente for, maior será representado dentro da nuvem. O contrário também é verdadeiro. Assim, para que as expressões ou frases utilizadas pelos interlocutores fossem interpretadas pelo software como um único termo, o espaço entre as palavras foi preenchido com um hífen “-”. Para preservar as identidades dos sujeitos da pesquisa, esses foram cognominados por P1, P2 e P3 (aqueles que assumiram a função docente) e A1, A2, A3, [...], A14 (aqueles que assumiram a função discente).

Para comparar as principais expressões utilizadas nos inícios e nos finais dos comentários dos sujeitos que ocuparam as funções docente e discente neste fórum, foram destacados os dois maiores elementos de cada nuvem de palavras, ou seja, as duas expressões mais recorrentes. Tal comparação pode ser verificada a partir do quadro 1. 
Quadro 1 - Expressões mais recorrentes nas acolhidas e despedidas do fórum de discussão.

\begin{tabular}{|c|c|}
\hline $\begin{array}{c}\text { Início das interações ou saudações dos sujeitos } \\
\text { que ocupavam a posição discente }\end{array}$ & $\begin{array}{l}\text { Início das interações ou saudações dos sujeitos que } \\
\text { ocupavam a posição docente }\end{array}$ \\
\hline $\begin{array}{l}\text { - Olá Colegas! } \\
\text { - Boa noite caríssimos colegas! }\end{array}$ & $\begin{array}{l}\text { - Olá A9! } \\
\text { - Olá A8! }\end{array}$ \\
\hline $\begin{array}{l}\text { Final ou despedida dos sujeitos que ocupavam a } \\
\text { posição discente }\end{array}$ & $\begin{array}{l}\text { Final ou despedida dos sujeitos que ocupavam a } \\
\text { posição docente }\end{array}$ \\
\hline $\begin{array}{l}\text { - Vamos conversando! } \\
\text { - Abraço a todos! }\end{array}$ & $\begin{array}{l}\text { - Vamos conversando! } \\
\text { - Um forte abraço! }\end{array}$ \\
\hline
\end{tabular}

Fonte: Fórum de discussão "Cordel no ensino de Física".

O que se verifica é que, nas despedidas, todos se preocuparam em dialogar com todos (interação todos-todos). No entanto, chama atenção nas saudações, ou interações iniciais mais recorrentes, aqueles que ocuparam a função discente dialogarem com todos (um-todos) enquanto aqueles que ocuparam a função docente estarem mais preocupados em dialogar um a um (um-um).

Os professores se preocuparam em dar um feedback personalizado a cada um dos sujeitos que ocupavam a função discente provocando-os a continuar contribuindo no fórum. No entanto, tal esforço reduziu as possibilidades de interlocução com outros sujeitos, pois para atender às provocações daqueles que ocuparam a função docente, o feedback dos alunos precisava responder diretamente aos professores.

Já é conhecido que existe uma tendência dos professores, mesmo aqueles que discutem a temática da educação online e que buscam um modelo interativo e flexível para a sala de aula, de reproduzirem nos AVA as práticas expositivas que classicamente posicionam o professor como a figura central. Segundo Moran (2012, p. 46), os professores, mesmo aqueles que atuam em AVA, ainda "insistem em utilizar predominantemente métodos expositivos com alguma (pouca) interação". Isso indica que educar em AVA "exige mais dedicação do professor, mais apoio de uma equipe técnico-pedagógica, mais tempo de preparação [...] e principalmente de acompanhamento" (MORAN, 2012, p. 51). De forma análoga, também se exige mais daqueles que ocupam a função discente porque "em sala de aula interativa não se professora sem a participação [ativa] dos aprendizes" (SILVA, 2012b, p. 54, grifo nosso).

\section{II.4 A topologia da rede social construída no fórum}

Para que se possa visualizar a topografia das interações desenvolvidas nessa sala de aula, uma alternativa apresentada por Silva, Lessa e Mercado (2015) foi mapeá-las por meio do software CmapTools. Para Recuero (2011), os sujeitos interagentes - ou na perspectiva da teoria ator-rede, atores sociais - são o primeiro elemento que constitui a rede social e no mapeamento das interações são representados graficamente por nós ou nodos. 
A análise de uma rede social constituída a partir das interações entre os sujeitos se dá, por analogia, com estruturas já conhecidas e não se preocupa em analisar o discurso/fala/conversa desses atores. Nesse sentido, Recuero (2011) considera que as principais topologias de redes sociais na internet são as seguintes: a) distribuída; b) centralizada; e c) descentralizada. A rede centralizada é aquela na qual um único nó concentra a maioria das conexões; a rede descentralizada é aquela que possui poucos nós altamente conectados e muitos nós pouco conectados; já a rede distribuída é aquela em que os nós apresentam mais ou menos a mesma quantidade de conexões (distribuição randômica).

Ao fazer uma analogia das topografias de redes sociais apresentadas por Recuero (2011) com as possibilidades de topografias de redes sociais que podem ser construídas nos fóruns online, é possível observar que, dependendo da finalidade do fórum, a dinâmica das interações em seu interior pode se aproximar de um determinado modelo topográfico. Em fóruns cujo objetivo é tirar dúvidas com o professor ou o tutor, por exemplo, o nó central geralmente representa a figura docente. Ao mapearmos a topografia da rede social construída nesse tipo de fórum, observaremos uma rede centralizada na qual um único nó concentra a maioria das conexões. Em fóruns nos quais dois ou três sujeitos mais empenhados interagem de forma mais intensa e os demais apenas respondem à provocação desse sujeito, por exemplo, observaremos uma estrutura com alguns poucos nós altamente conectados e uma grande quantidade de nós pouco conectados. Já em salas de aula online nas quais a maioria dos sujeitos está empenhada em interagir uns com os outros, o número de conexões tende a se uniformizar e se distribuir de forma randômica. Nesse sentido se observa diferentes possibilidades para as topografias das interações nas salas de aula online.

O que se pode deduzir, em diálogo com as topografias apresentadas por Recuero (2011), é que, o que se busca para as salas de aula online são topografias cada vez mais próximas de uma distribuição randômica. Silva (2012b) chamou esses modelos de paradigmas comunicacionais da sala de aula. São eles: a sala de aula unidirecional (comunicação umtodos, na qual um único nó concentra a maioria das conexões) e a sala de aula interativa (comunicação todos-todos, de topografia randômica). Assim, no primeiro cenário (sala de aula unidirecional), um único sujeito ocupa o centro de sala de aula e transmite as informações para os demais. Fica demarcada a função docente, que nesse caso é a de transmitir as informações. Já no segundo cenário, a função de transmitir informações se desfaz e todos interagem com todos. Os sujeitos, nesse segundo caso, são responsáveis por sua própria aprendizagem e pela aprendizagem de seus pares.

Diante de tais modelos foi realizado, com base na metodologia proposta por Silva, Lessa e Mercado (2015), o mapeamento das interações no fórum intitulado "O Cordel no Ensino de Física". A princípio, as interações registradas foram mapeadas de acordo como grau de conexão entre os sujeitos, densidade das interações e centralidade dos nodos. O resultado desse mapeamento, realizado com o auxílio do software CmapTools pode ser visto a partir da Fig. 4. 


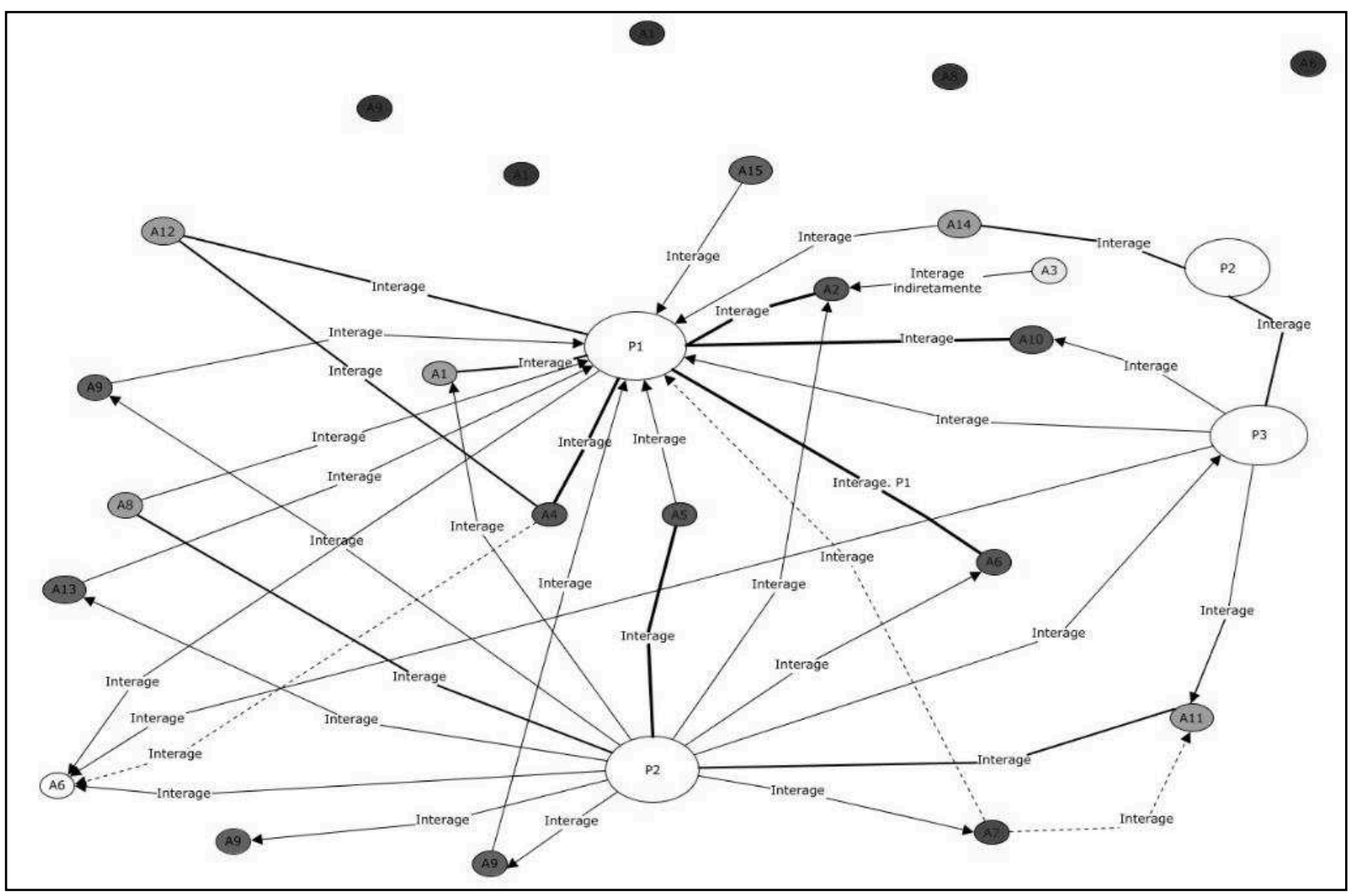

Fig. 4 - Topografia da sala de aula constituída no fórum "O cordel no ensino de Física".

Fonte: Os autores.

A partir da Fig. 4 é possível apontar diversos níveis de interação. Os nodos representam os sujeitos e as conexões representam as interações entre eles. Ao observar essa figura, é possível verificar que as conexões são majoritariamente simétricas, o que sugere que a maioria dos sujeitos interagiu mais ou menos com a mesma quantidade de interlocutores, exceto no caso dos nodos P1, P2, P3 e A6. Nesses nodos, a densidade de conexões é radicalmente maior que no caso dos nodos A1, A2, A3, [...] A14.

Outro dado que nos chama atenção na Fig. 4 é a presença de nodos que gravitam em torno da rede de conexões como satélites do fórum. Esses nodos representam os sujeitos que contribuíram com mensagens no fórum, mas não as direcionaram aos professores, ou ao grupo ou a algum colega em específico. Em consequência desse não direcionamento, nenhum outro colega ou professor interagiu de forma direta com esses sujeitos.

Como resultados dessa análise topográfica, o que se constata é que: a) dos 18 sujeitos que compunham a disciplina "Temas de Física na pesquisa-formação de professores", 17 participaram do fórum; b) a topologia das interações no fórum de discussão do módulo 5, "O Cordel no Ensino de Física", apresentou poucos nodos altamente conectados e muitos nodos pouco conectados, sugerindo a topografia de ume rede descentralizada; c) ao verificar os sujeitos representados pelos nodos altamente conectados, observou-se que, embora tenha havido um esforço para a superação desse modelo, a sala de aula constituída se manteve centrada na 
figura docente; d) de forma análoga à sala de aula convencional, embora em menor proporção, pode-se observar sujeitos que estão presentes no AVA, mas que se mantém nos níveis mínimos de interação, ocupando uma posição passiva mesmo quando o objetivo é construir uma sala de aula interativa; e) ao confrontar os dados obtidos na Fig. 4, com os dados obtidos no quadro 1, é possível constatar que apesar das intervenções dos sujeitos que ocuparam a posição discente indicarem majoritariamente uma comunicação todos-todos; do desenho didático estar apoiado na flexibilidade e na interatividade do ciberespaço; e do material didático ter sido produzido de forma dialógica, multimidiática e hipertextual; as intervenções dos sujeitos que ocuparam a posição docente acabaram por centralizar as interações no fórum, resultando numa topografia descentralizada e caracterizando um modelo intermediário entre a sala de aula tradicional (paradigma comunicacional um-todos) e a sala de aula interativa (paradigma comunicacional todos-todos).

\section{Considerações finais}

A construção da disciplina "Temas de Física na pesquisa-formação de professores" resultou de um movimento que teve em seu bojo o desafio de explorar e socializar o conhecimento na área de Educação em Ciências e fortalecer a parceria entre pesquisadores geograficamente distantes. Desafio aceito, o que se conseguiu foi reunir sujeitos de diferentes países, distribuídos em variados municípios brasileiros das regiões Sul e Nordeste, de diferentes faixas etárias, credos, etnias, gêneros, orientações sexuais, níveis econômicos e de formação acadêmica. $\mathrm{O}$ respeito a essa diversidade, imprescindível na sociedade, perpassou toda essa experiência de pesquisa-formação e foi sua marca registrada.

Da análise e dos resultados da topografia da sala de aula construída no módulo 5, o que se observou é que é preciso conduzir os processos formativos na direção de uma docência online que ao invés de assentada na pedagogia da transmissão (paradigma comunicacional um-todos), estimule a criação de uma sala de aula interativa (paradigma comunicacional todos-todos). Esse é um problema ainda não resolvido nos cursos de formação de professores sejam eles de graduação ou pós-graduação. Mesmo nesta experiência em que o objetivo central era o de superar modelos centralizados na figura do professor, observa-se que esse paradigma, embora tenha sido fortemente questionado, persistiu.

O feedback rápido e individual continua sendo imprescindível na educação online, no entanto, é igualmente fundamental que não se perca de vista que, se o que se busca é a construção de uma sala de aula interativa, nem o professor nem alguns poucos alunos podem ocupar o centro do palco.

A construção de uma sala de aula interativa na qual todos interagem com todos exige uma distribuição randômica na quantidade e na qualidade das interações entre os sujeitos. Nesse sentido, exige-se mais, tanto dos professores quanto dos alunos. Esse cenário não comporta alunos passivos e também não comporta professores centralizadores. É preciso caminhar na direção de uma práxis que contribua para superação da polarização clássica na sala de aula 
tradicional: aluno-passivo / professor-ativo. Esse é um desafio que permanece no cenário contemporâneo e que doravante está lançado a outros sujeitos que, instigados por experiências como essa, possam explorar mais e melhor os caminhos da pesquisa-formação.

\section{Referências}

ALMEIDA, M. G. Importância da mediação pedagógica nos textos didáticos escritos para a educação a distância. In: MERCADO, L. P. (Org.). Fundamentos e práticas na educação a distância. Maceió: Edufal, 2009, p. 97-112.

ALMEIDA, M. G.; CAVALCANTE, P. S. Elementos de análise de textos didáticos escritos para a educação a distância. In: MERCADO, L. P. (Org.). Fundamentos e práticas na educação a distância. Maceió: Edufal, 2009, p. 53-66.

BELISÁRIO, A. O material didático na educação a distância e a constituição de propostas interativas. In: SILVA, M. (Org.). Educação online: teorias, práticas, legislação, formação corporativa. 4. ed. São Paulo: Edições Loyola, 2012b. p. 137-148.

BLIKSTEIN, P.; ZUFFO, M. K. As sereias do ensino eletrônico. In: SILVA, M. (Org.). Educação online: teorias, práticas, legislação, formação corporativa. 4. ed. São Paulo: Edições Loyola, 2012b. p. 25-40.

COSTA, C. J; MOTTA FILHO, L. G. Um modelo para a gestão da qualidade do material didático na educação a distância. In: MERCADO, L. P. (org.). Fundamentos e práticas na educação a distância. Maceió: Edufal, 2009, p. 67-82.

COSTA, C. J.; PARAGUAÇU, F. Possibilidades de coletas de dados para pesquisa no contexto da internet. In: COSTA, C. J.; MERCADO, L. P. (Orgs.). Pesquisa em educação online. Maceió: Edufal, 2011, p. 09-20.

FLICK, U. Introdução à pesquisa qualitativa. 3. ed. Porto Alegre: Artmed, 2009.

GOMES, L. F. Hipertexto no cotidiano escolar. São Paulo: Cortez, 2011.

HECKLER, V. et al. O desenvolver metodológico na pesquisa-formação de professores da experimentação em ciências online. In: CONGRESSO BRASILEIRO DE ENSINO SUPERIOR A DISTÂNCIA, 10, 2013, Belém-PA. Anais... Belém-PA: UFPA/UNIREDE. 2013.

KOCH, I. V. Desvendando os segredos do texto. 6. ed. São Paulo: Cortez, 2009.

KUENZER, A. Z. Competência como práxis: os dilemas da relação entre teoria e prática na educação dos trabalhadores. Boletim técnico do SENAC, v. 29, n. 1, p. 16-27, 2018.

MACEDO, R. M. et al. Perfis bibliométrico e temático da produção científica disponível na SciELO relacionada ao hipertexto. Revista EDaPECI, v. 17, n. 03, p. 140-151, 2017. 
MARCUSCHI, L. A. O hipertexto como um novo espaço de escrita em sala de aula. Linguagem \& Ensino, v. 4, n. 1, p. 79-111, 2001.

MORAN, J. M. Contribuições para a pedagogia da educação online. In: SILVA, M. (Org.). Educação online: teorias, práticas, legislação, formação corporativa. 4. ed. São Paulo: Edições Loyola, 2012b. p. 41-52.

NUNES, A. Karla F.; LIMA, I. C. Hipertexto na visão de sentidos múltiplos no mundo tecnológico. Revista EDaPECI, v. 18, n. 1, p. 71-76, 2018.

RECUERO, R. Redes sociais na internet. Porto Alegre: Sulina, 2011.

REZENDE, F.; COLA, C. S. D. Hipermídia na educação: flexibilidade cognitiva, interdisciplinaridade e complexidade. Ensaio: Pesquisa em Educação em Ciências, Belo Horizonte, v. 6, n. 2, p. 94-104, dez. 2004.

RIBEIRO, M. R.; SANTOS, E. Pesquisa-formação multirreferencial e com os cotidianos na cibercultura: tecendo a metodologia com um rigor outro. Revista de Educação Pública, v. 25, n. 59, 2016.

SAMPIERI, R. H.; CALLADO, C. F.; LÚCIO, M. P. Metodologia de pesquisa. 5. ed. Porto Alegre: Penso, 2013.

SANTOS, E. Educação online como dispositivo na ciberpesquisa-formação. Revista Tecnologias na Educação v. 20, 2017.

SANTOS, E.; SANTOS, W. J.; SILVA, I. P. Possibilidades didáticas do uso da literatura de cordel para o ensino de física. Material didático do módulo 5 - Cordel no ensino de física. Disciplina Temas de Física na pesquisa-formação de professores. Programa de pósgraduação em educação em ciências. Programa de pós-graduação em ensino de física. Universidade Federal do Rio Grande. Segundo semestre, 2017.

SANTOS, E.; SILVA, M. O desenho didático interativo na educação online. Revista Iberoamericana de educación, v. 49, p. 267-287, 2009.

SILVA, A. L. S.; FIGUEIREDO, L. K. Do texto ao hipertexto: reflexões acerca da leitura de jornais impressos e digitais na sala de aula. Revista EDaPECI, v. 13, n. 3, p. 391-402, 2013.

SILVA, I. P.; LESSA, R. K.; MERCADO, L. P. Mediação pedagógica em fóruns de discussão no contexto da experiência do estágio de docência online. Revista EDaPECI, v. 15, n. 1, p. 30-56, 2015.

SILVA, M. (Org.). Educação online: teorias, práticas, legislação, formação corporativa. 4. ed. São Paulo: Edições Loyola, 2012a. 
SILVA, M. Criar e professorar um curso online: relato de experiência. In: SILVA, M. (Org.). Educação online: teorias, práticas, legislação, formação corporativa. 4. ed. São Paulo: Edições Loyola, 2012b. p. 53-76.

(cc) BY-NC-ND Direito autoral e licença de uso: Este artigo está licenciado sob uma Licença Creative Commons. 